International Journal of Advanced Technology in Mechanical, Mechatronics and Materials

(IJATEC)

Vol. 01, No. 1 (2020) 18-25

(C) Institute for Research on Innovation and Industrial System (IRIS)

\title{
Opacity Results Diesel Fuel: Bio Solar, Dexlite, Dex and Analysis Theoretical Flammability Limit
}

\author{
Hadi Pranoto*a, Wiwit Suprihatiningsiha, Muhammad Idil Fadila, Supaat Zakariab \\ a Department of Mechanical Engineering, Faculty of Engineering, Universitas Mercu Buana, Jakarta, Indonesia \\ ${ }^{b}$ Faculty of Engineering Technology, Polytechnic Ungku Omar, Malaysia
}

\begin{abstract}
Each mixture of fuel and gas has a different flame speed. Gas will only burn at a suitable percentage of air and produce different exhaust gas opacity. Opacity is a ratio of the rate of light absorption by smoke expressed in units of percent. This study aims to theoretically analyse the relationship between the flammability limit and the variation of fuel which has a different setana number associated with the exhaust gas opacity value of the engine performance test equipment. The machine performance test equipment used is the L300 engine. The methodology used is the testing of exhaust gas opacity using the Koeng OP-201 opacity meter and theoretically analysed its relationship with the bio solar, dexlite and pertamina dex flame limits. The results of this study found that bio solar has an upper flame limit of $6.65 \%$, a lower flame limit of $0.53 \%$, and an average opacity value of $12.1 \%$. Dexlite has an upper limit of $6.70 \%$, a lower limit of $0.53 \%$, and an average opacity value of $10.5 \%$. Pertamina dex has an upper limit of $6.68 \%$, a lower limit of $0.53 \%$, and an average opacity value of $9.21 \%$.
\end{abstract}

Keywords: biosolar fuel; flammability limit; opacity

DOI: $10.37869 /$ ijatec.v1i1.10

Received 5 March 2020; Accepted 22 March 2020; Available online 30 March 2020

(c) 2020 IRIS Publisher. All rights reserved.

\section{Introduction}

A combustion that occurs in diesel engines is different from gasoline engines. Diesel engines start combustion by utilizing heat from compressed air. The combustion process that utilizes heat from compressed air, makes diesel fuel must be able to mix with air. In reality, the occurrence of a flame can be achieved if there is a mixture of oxidizing and supporting fuel. There is a range of fuel and oxidizing mixtures that can cause a flame. This range is the range of the lower limit of flammability and the upper limit of flammability or better known as the lower and upper flammability limits. Pertamina as BUMN that processes energy sources in Indonesia issues three types of diesel fuel, namely bio solar, dexlite, and pertamina dex [23].

Combustion will produce exhaust gas or emissions. The fuel used also affects the exhaust gas produced. The dominant element in diesel engine exhaust gases is SO2 and C which cause smoke density. To measure the exhaust gas content, measuring devices are needed so that the type and amount are known. The measuring instrument commonly used is the opacity meter.

Recent works emphasized the importance of this topic, too. Takahashi et al. [1] tested the flammability of methane and propane using reactors of different shapes and established their minimum dimensions so as to obtain open-space propagation. Several works discussed the effect of ignition energy on the measurements, and the difference between ignitability and flammability limits [1]-[4]. Wierzba and Wang [5] noticed the wall catalytic effect of capturing $\mathrm{H} 2$ before testing and found out that quartz walls are preferable to steel ones. The first data on flammability limits were .

*Corresponding author: hadi.pranoto@mercubuana.ac.id ISSN: 2720-9008 
obtained using a constant pressure, $1.5 \mathrm{~m}$ long vertical tube with bottom ignition and no ceiling [6]. ASTM [21,22] proposed a standardized procedure to measure flammability limits in a closed, spherical, and remotely controlled vessel, fitted with pressure and temperature transducers. The latter experimental setup has been widely used in literature [7]. The review by Britton [8] attributed a major reliability to this apparatus and discussed the applicability of different criteria to experimentally determine the flammable range. The effect of the vessel volume and shape [1], possible catalytic effect of the walls [9], the choice of the detecting criterion [9], and the accuracy of the measurement tools for temperature, pressure and composition constitute the sources of uncertainty related to the experiments, which has been rarely quantified. In general, increasing temperature and pressure corresponds to broadening the flammable range [9], [10]. Chen et al. [9] observed the influence of pressure on the increase of buoyancy and the resulting anticipated extinction. The same phenomenon was observed while determining flame speeds in a spherical reactor near flammability limits [7], where they found this effect to be negligible for pressures higher than $5 \mathrm{~atm}$.

The influence of oxygen content on the flammable range was also extensively studied: as known, increasing its amount broadens the range[11], [12] whereas it, depletion leads to a reduction of the difference between UFL and LFL, up to the limiting oxygen concentration (LOC), where they coincide. Changing the oxidizer from air to pure 02, or nitrous oxide (N20), can influence the limits to a significant extent [2][13], and the presence of steam [8] or CO2 [14] within the oxidizer was shown to suppress flammable limits. Finally, Law et al. [14] showed the effect of flame stretch on flammability limits. In this scenario, a comprehensive and validated theoretical approach for predicting the flammable ranges of pure fuels and their mixtures would be of the utmost importance within the fire safety community.

A formal and theoretical definition of flammability limit was provided by Williams [15], which involves the failure of the propagation of the ideal one-dimensional, steady, laminar, planar, adiabatic flame. Lakshmisha et al. [6], [16] stated the importance of the inclusion of a radiative term for modeling heat losses. Egolfopoulos et al. [17] proposed a "chain-thermal" theory, based on the definition from Williams [15] and the assumption that the competition between branching and termination reactions drives the combustion process nearby the flammability limits, where the flame front propagation slows down, and the heat losses become important [31]. They cause flame temperature to decrease downstream the reaction zone, modifying the reaction pathways and reducing the reaction rates. A Freely Propagating Flame (FPF) model with detailed kinetics was adopted to investigate the LFL of methane and propane, and an optically thin gas radiation model was introduced in order to couple heat losses and kinetics. Van den Schoor et al. [18] extended the work of Egolfopoulos et al. [17] to the UFL of methane at different initial conditions and compared the performance of several existing kinetic mechanisms. Also, Van den Schoor et al. [19] discussed the approximations intrinsically adopted using the FPF method and applied it to the prediction of the flammability limits of hydrogen/methane/air mixtures. Recently, this method was also used to evaluate the effect of ultra-low temperature on natural gas flammability limits [20]. Study of combustion processes in all combustion systems is one of the critical and complex problems. Combustors play an important role in determining the operational characteristics of turbine engines, such as flame stability [21].

\section{Methodology}

To achieve the objectives of this research, we propose a methodology, and this methodology consists of the steps of how we conduct diesel engine testing using the method of measuring the smoke thickness of the combustion results, using the opacity meter test, testing is performed with several engine speed parameters with different types of fuel, the results of the value of this smoke opacity will be compared with manual calculations to get an analysis of flamebility limits on each type of fuel. as shown in the flow chart research methodology Figure 2 with the implementation stages of the test described as follows, step 1 starting the implementation of the test with Analysis of Opacity Test Results on Biosolar Fuels, Dexlite, and Dex base on flamebillity limits analysis, and than step 2 -3 study literature and analysis flamebility and then step 4 emission testing with opasitas meter Figure 1. 


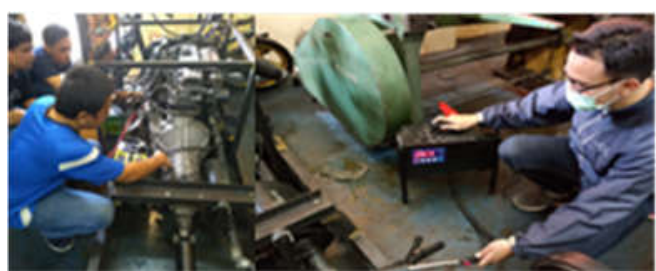

Figure 1. Opacity testing on diesel engine

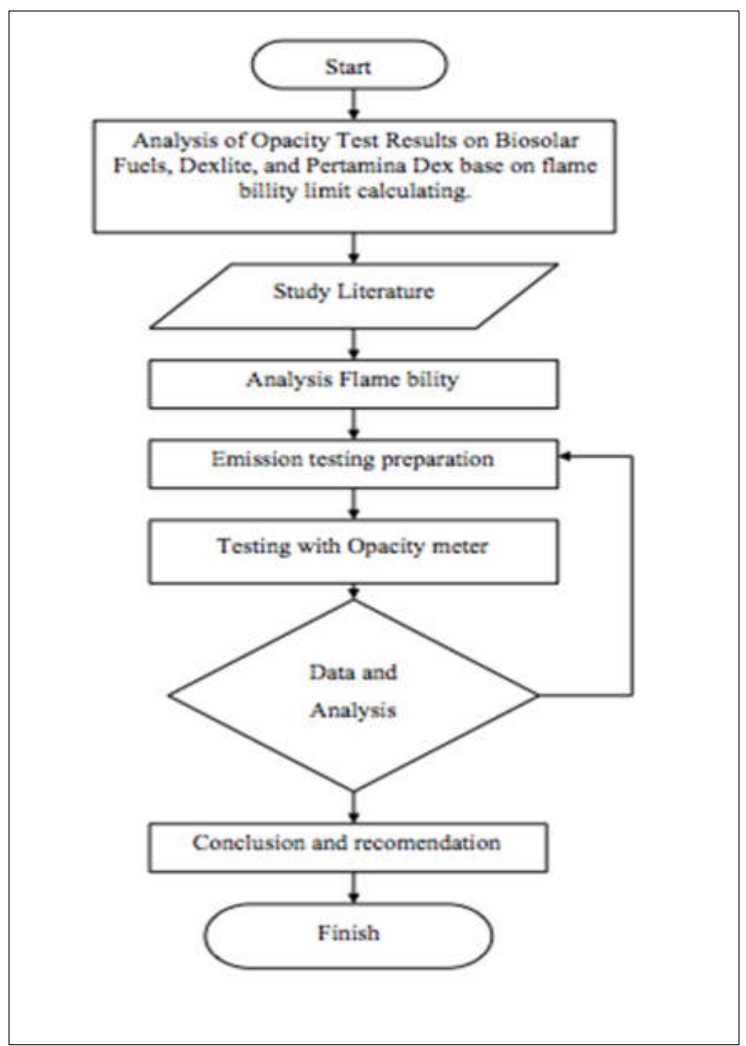

Figure 2. Specification of combustion speed analysis and opacity testing

\section{Results and Discussion}

From Pertamina data, it is found that the centane number of Biosolar fuel in Indonesia is $51 \%+$ alphamethylnapthalene $52 \%$, then Dexlite fuel, cetane number has a value of $51 \%+$ alphamethylnapthalene 49\%, then the highest type in Indonesia for diesel engine is Dex with centane number $53 \%$ +alpha-methylnapthalene $47 \%$.

Diesel fuel has a chemical reaction $\mathrm{C}_{16} \mathrm{H}_{34}+\mathrm{C}_{11} \mathrm{H}_{10}$ with cetane $\mathrm{C}_{16} \mathrm{H}_{34}$ and mixing alphamethylnapthalene $\mathrm{C}_{11} \mathrm{H}_{10}$.

$$
C_{n} H_{m}+\left(n+\frac{m}{4}\right)\left(O_{2}+3,773 N_{2}\right) \rightarrow n C O_{2}+\frac{m}{2} H_{2} O+3,773\left(n+\frac{m}{4}\right) N_{2}
$$

Then for the equation of combustion of hydrocarbons with oxygen in the can

$$
C_{n} H_{m}+\left(n+\frac{m}{4}\right) O_{2} \rightarrow n C O_{2}+\frac{m}{2} H_{2} \mathrm{O}
$$

- Biosolar fuels

Combustion reaction of bio-Solar in diesel engines in accordance with standard data obtained by the chemical reaction as follows 


$$
\begin{aligned}
& \mathrm{C}_{16} \mathrm{H}_{34}=48 \% \\
& 0,48\left(\mathrm{C}_{16} \mathrm{H}_{34}+24,5 \mathrm{O}_{2}+92,4 \mathrm{~N}_{2} \rightarrow 16 \mathrm{CO}_{2}+17 \mathrm{H}_{2} \mathrm{O}+94,2 \mathrm{~N}_{2}\right) \\
& 0,48 \mathrm{C}_{16} \mathrm{H}_{34}+11,76 \mathrm{O}_{2}+44,35 \mathrm{~N}_{2} \rightarrow 7,68 \mathrm{CO}_{2}+8,16 \mathrm{H}_{2} \mathrm{O}+44,35 \mathrm{~N}_{2} \\
& \mathrm{C}_{11} \mathrm{H}_{10}=52 \% \\
& 0,52\left(\mathrm{C}_{11} \mathrm{H}_{10}+13,5 \mathrm{O}_{2}+50,93 \mathrm{~N}_{2} \rightarrow 11 \mathrm{CO}_{2}+5 \mathrm{H}_{2} \mathrm{O}+50,93 \mathrm{~N}_{2}\right) \\
& 0,52 \mathrm{C}_{11} \mathrm{H}_{10}+7,02 \mathrm{O}_{2}+26,48 \mathrm{~N}_{2} \rightarrow 5,72 \mathrm{CO}_{2}+2,6 \mathrm{H}_{2} \mathrm{O}+26,48 \mathrm{~N}_{2}
\end{aligned}
$$

It is important to know that the composition of the Biosolar diesel fuel, which is tested, has a chemical composition as follows:

$$
\begin{aligned}
& O_{2}=11,76+7,02=18,78 \\
& N_{2}=44,35+26,48=70,83 \\
& C_{16} H_{34}=(100-(18,78+70,83)) x 0,48=4,98 \\
& \boldsymbol{C}_{\mathbf{1 1}} \boldsymbol{H}_{\mathbf{1 0}}=(\mathbf{1 0 0}-(\mathbf{1 8}, \mathbf{7 8}+\mathbf{7 0 , 8 3})) \boldsymbol{x} \mathbf{0 , 5 2}=\mathbf{5 , 4 0}
\end{aligned}
$$

Air is generally assumed to consist of two main components; oxygen and nitrogen with compositions as in Table 1.

Table 1. Components of air

\begin{tabular}{ccc}
\hline Element & Volume Percentage & Mass Percentage \\
\hline $\boldsymbol{O}_{\mathbf{2}}$ & 21 & 18,78 \\
$\boldsymbol{N}_{\mathbf{2}}$ & 79 & 70,83 \\
\hline
\end{tabular}

Possibility 1 and 2 and not possible states that the composition of the Bio solar diesel fuel, by default, is calculated from equation 12

$$
\begin{aligned}
& \mathrm{O}_{2}=18,78 \%=0,1878 \mathrm{~mol} \\
& N_{2}=\frac{79}{21} \times 0,1878=0,706 \approx 70,6 \%
\end{aligned}
$$

Possible, because $70,6 \% \leq 70,83 \%$

Possibility 2

$$
\begin{aligned}
& N_{2}=70,83 \%=0,7083 \\
& O_{2}=\frac{21}{79} \times 0,7083=0,1882 \approx 18,82 \%
\end{aligned}
$$

Not Possible

$N_{2}$ residual $=0,7083-0,706=0,0023$

Residual fuel $=1-0,1878-0,706=0,1062$

Composition of new fuel

$$
\begin{aligned}
& N_{2}=\frac{0,0023}{0,1062} \times 100 \%=2,17 \% \\
& C_{16} H_{34}=\frac{0,0498}{0,1062} \times 100 \%=46,89 \% \\
& C_{11} H_{10}=\frac{0,054}{0,1062} \times 100 \%=50,85 \%
\end{aligned}
$$

Table 2 explains the upper and lower flame limits of diesel fuel

Table 2. Flame limits of diesel fuel

\begin{tabular}{ccc}
\hline Element & Upper limit & Lower limit \\
\hline$C_{16} H_{34}$ & 6,5 & 0,4 \\
$C_{11} H_{10}$ & 6,5 & 0,7 \\
\hline
\end{tabular}


The flame can spread through the gas mixture to only one particular composition constraint. Although in practical use it is often mentioned that gas or vapor from metane, propane, and acetone are flammable compounds, but the mixture with air will only be read if the composition of the fuel mixture is at a certain limit, namely the lower flame limit (lower flamebility limits) and upper flammability limits.

The results of the analysis of the upper and lower ignition limit of biosolar fuels can be seen in the following description:

Upper limits $=\frac{100 \%}{\frac{46,89}{6,5}+\frac{50,85}{6,5}}=\frac{100 \%}{7,21+7,82}=6,65 \%$

Lower limits $=\frac{100 \%}{\frac{46,89}{0,4}+\frac{50,85}{0,7}}=\frac{100 \%}{117,22+72,64}=0,53 \%$

- Dexlite fuels

Combustion reaction of Dexlite Fuel in diesel engines in accordance with standard data obtained by the chemical reaction as follows

$$
\begin{aligned}
& \mathrm{C}_{16} \mathrm{H}_{34}=51 \% \\
& 0,51\left(\mathrm{C}_{16} \mathrm{H}_{34}+24,5 \mathrm{O}_{2}+92,4 \mathrm{~N}_{2} \rightarrow 16 \mathrm{CO}_{2}+17 \mathrm{H}_{2} \mathrm{O}+94,2 \mathrm{~N}_{2}\right) \\
& 0,51 \mathrm{C}_{16} \mathrm{H}_{34}+12,49 \mathrm{O}_{2}+47,12 \mathrm{~N}_{2} \rightarrow 8,16 \mathrm{CO}_{2}+8,67 \mathrm{H}_{2} \mathrm{O}+47,12 \mathrm{~N}_{2} \\
& \mathrm{C}_{11} \mathrm{H}_{10}=49 \% \\
& 0,49\left(\mathrm{C}_{11} \mathrm{H}_{10}+13,5 \mathrm{O}_{2}+50,93 \mathrm{~N}_{2} \rightarrow 11 \mathrm{CO}_{2}+5 \mathrm{H}_{2} \mathrm{O}+50,93 \mathrm{~N}_{2}\right) \\
& 0,49 \mathrm{C}_{11} \mathrm{H}_{10}+6,61 \mathrm{O}_{2}+24,95 \mathrm{~N}_{2} \rightarrow 5,39 \mathrm{CO}_{2}+2,45 \mathrm{H}_{2} \mathrm{O}+24,95 \mathrm{~N}_{2}
\end{aligned}
$$

It is important to know that the composition of the Dexlite diesel fuel, which is tested, has a chemical composition as follows

$$
\begin{aligned}
& O_{2}=12,49+6,61=19,1 \\
& N_{2}=47,12+24,95=72,07 \\
& C_{16} H_{34}=(100-(19,1+72,07)) \times 0,51=4,50 \\
& C_{11} H_{10}=(100-(19,1+72,07)) \times 0,49=4,33
\end{aligned}
$$

Possibility 1 and 2 and not possible states that the composition of the Dexlite diesel fuel, by default, is calculated from equation 11

$O_{2}=19,1 \%=0,191 \mathrm{~mol}$

$N_{2}=\frac{79}{21} \times 0,191=0,718 \approx 71,8 \%$

Possible, because $71,8 \% \leq 72,07 \%$

$$
\begin{aligned}
& N_{2}=72,07 \%=0,7207 \\
& O_{2}=\frac{21}{79} \times 0,7207=0,1915 \approx 19,15 \%
\end{aligned}
$$

Not possible

$$
\begin{aligned}
& N_{2} \text { residual }=0,7207-0,718=0,0027 \\
& \text { Residual fuel }=1-0,191-0,718=0,091
\end{aligned}
$$

Composition of new fuel is calculated based on the calculation results that have been analyzed in equations 12 and 13

$$
\begin{aligned}
& N_{2}=\frac{0,0027}{0,091} \times 100 \%=2,97 \% \\
& C_{16} H_{34}=\frac{0,0450}{0,091} \times 100 \%=49,45 \% \\
& C_{11} H_{10}=\frac{0,0433}{0,091} \times 100 \%=47,58 \%
\end{aligned}
$$


To determine whether a gas is flammable and to estimate the upper and lower flame limits of a gas in Dexlite fuel can be seen in the following description:

Upper limits flammable $=\frac{100 \%}{\frac{49,45}{6,5}+\frac{47,58}{6,5}}=\frac{100 \%}{7,61+7,32}=6,7 \%$

Lower limits flammable $=\frac{100 \%}{\frac{49,45}{0,4}+\frac{47,58}{0,7}}=\frac{100 \%}{123,62+67,97}=0,52 \%$

- Dex diesel fuel

Combustion reaction of Dex Diesel Fuel in diesel engines in accordance with standard data obtained by the chemical reaction as follows:

$$
\begin{aligned}
& \mathrm{C}_{16} \mathrm{H}_{34}=53 \% \\
& 0,53\left(C_{16} \mathrm{H}_{34}+24,5 \mathrm{O}_{2}+92,4 \mathrm{~N}_{2} \rightarrow 16 \mathrm{CO}_{2}+17 \mathrm{H}_{2} \mathrm{O}+94,2 \mathrm{~N}_{2}\right) \\
& 0,53 \mathrm{C}_{16} \mathrm{H}_{34}+12,98 \mathrm{O}_{2}+48,97 \mathrm{~N}_{2} \rightarrow 8,48 \mathrm{CO}_{2}+9,01 \mathrm{H}_{2} \mathrm{O}+48,97 \mathrm{~N}_{2} \\
& C_{11} \mathrm{H}_{10}=47 \% \\
& 0,47\left(C_{11} \mathrm{H}_{10}+13,5 \mathrm{O}_{2}+50,93 \mathrm{~N}_{2} \rightarrow 11 \mathrm{CO}_{2}+5 \mathrm{H}_{2} \mathrm{O}+50,93 \mathrm{~N}_{2}\right) \\
& 0,47 \mathrm{C}_{11} \mathrm{H}_{10}+6,34 \mathrm{O}_{2}+23,94 \mathrm{~N}_{2} \rightarrow 5,17 \mathrm{CO}_{2}+2,35 \mathrm{H}_{2} \mathrm{O}+23,94 \mathrm{~N}_{2}
\end{aligned}
$$

It is important to know that the composition of the Dex Diesel Fuel, which is tested, has a chemical composition as follows:

$$
\begin{aligned}
& O_{2}=12,98+6,34=19,32 \\
& N_{2}=48,97+23,94=72,91 \\
& C_{16} H_{34}=(100-(19,32+72,91)) \times 0,53=4,12 \\
& C_{11} H_{10}=(100-(19,32+72,91)) \times 0,47=3,65
\end{aligned}
$$

Possibility 1 and 2 and not possible states that the composition of the Dex diesel fuel, by default, is calculated from equation 16

$$
\begin{aligned}
& O_{2}=19,32 \%=0,1932 \mathrm{~mol} \\
& N_{2}=\frac{79}{21} \times 0,1932=0,727 \approx 72,7 \%
\end{aligned}
$$

Possible, because $72,7 \% \leq 72,91 \%$

Possibility 2

$$
\begin{aligned}
& N_{2}=72,91 \%=0,7291 \\
& O_{2}=\frac{21}{79} \times 0,7291=0,1938 \approx 19,38 \% \\
& \text { Not possible } \\
& N_{2} \text { residual }=0,7291-0,727=0,0021
\end{aligned}
$$

Residual fuel $=1-0,1932-0,727=0,0798$

Composition of new fuel is calculated based on the calculation results that have been analyzed in equations 17 and 18

$$
\begin{aligned}
& N_{2}=\frac{0,0021}{0,0798} \times 100 \%=2,63 \% \\
& C_{16} H_{34}=\frac{0,0412}{0,0798} \times 100 \%=51,63 \% \\
& C_{11} H_{10}=\frac{0,0365}{0,0798} \times 100 \%=45,74 \%
\end{aligned}
$$

To determine whether a gas is flammable and to estimate the upper and lower flame limits of a gas in Dex Diesel Fuel can be seen in the following description:

Upper limits flammable $=\frac{100 \%}{\frac{51,63}{6,5}+\frac{45,74}{6,5}}=\frac{100 \%}{7,79+7,04}=6,74 \%$ 
Lower limits flammable $=\frac{100 \%}{\frac{51,63}{0,4}+\frac{45,74}{0,7}}=\frac{100 \%}{126,57+65,34}=0,52 \%$

\subsection{Opacity testing}

In a diesel engine, performance test equipment, emission or exhaust gas opacity tests with a variety of fuels are used. Bio solar, Dexlite, and Pertamina Dex are put into the fuel tank then the engine is started. After the engine is overheated or approximately 5 minutes after starting it. A probe from the opacity meter is inserted into the exhaust hole to measure the opacity produced by the engine performance test kit. Table (4) below shows the different exhaust gas opacity values of each bio solar, dexlite, and Pertamina dex.

Table 3. Opacity test result

\begin{tabular}{llcccc}
\hline \multirow{2}{*}{ No } & \multirow{2}{*}{ Fuel } & \multicolumn{3}{c}{ Opacity (\%) } & Average \\
& & 1 & 2 & 3 & (\%) \\
\hline 1 & Biosolar & 12,67 & 12,9 & 12,37 & 12,64 \\
2 & Dexlite & 10,53 & 10,53 & 10,47 & 10,51 \\
3 & Pertamina Dex & 7,73 & 7,83 & 7,77 & 7,77 \\
\hline
\end{tabular}

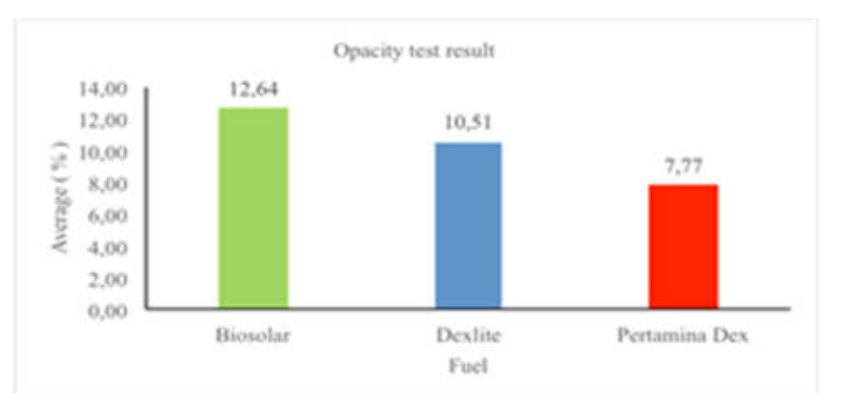

Figure 3. Opacity result Biosolar, Dexlite anda Dex Diesel Fuel

\section{Conclusions}

The cetane number in diesel fuel is directly proportional to the limit value of the flame. The greater the setana number, the greater the value of the flame limit. Pertamina dex with setana 53 has an upper limit of $6.74 \%$ and a lower limit of $0.52 \%$.

It is known that the opacity value is inversely proportional to the value of the flame limit and the cetane value of diesel fuel. The greater the cetane number and the fuel flame limit value, the resulting exhaust gas opacity value is smaller.

\section{Acknowledgment}

This research was supported/partially supported by Universitas Mercu Buana. We thank our colleagues from Politeknik Ungku Omar, Malaysia who provided insight and expertise that greatly assisted the research, although they may not agree with all of the interpretations/conclusions of this paper.

\section{References}

[1] S. K. A. Takahashi, Y. Urano, K. Tokuhashi, Effect of the vessel size and shape on experimental flammability limits of gases. . Hazard. Mater, 2003.

[2] J. E. S. U.J. Pfahl, M.C. Ross, Flammability limits, ignition energy, and flame speeds in H2-CH4NH3-N2O-O2-N2, Combust. Flame, 2000.

[3] M. G. Zabetakis, "No Title," Bureau of Mines, 1965, p. Flammability characteristics of combustible gases.

[4] G. W. J. H.F. Coward, "Limits of flammability of gases and vapors," Bureau of Mines, 1952. 
[5] K. H. H. Y.M. Chang, J.M. Tseng, C.M. Shuand, Flammability studies of benzene and methanol with various vapour mixing ratios at $150^{\circ} \mathrm{C}$. Korean J. Chem. Eng, 2005.

[6] H. S. M. K.N. Lakshmisha, P.J. Paul, K.S. Rajan, G. Goyal, "Behaviour of methane-oxygen-nitrogen mixtures near flammability limits," pp. 1573-1578, 1988.

[7] F. L. Z. Chen, X. Qin, B. Xu, Y. Ju, Studies of radiation absorption on flamespeed and flammability limit of carbon dioxide diluted methane flames at elevated pressures, 31st ed. Proc. Combust. Inst, 2007.

[8] L. B. M.J. Degges, J.E. Boyer, K.K. Kuo, "Influence of steam on the flammability limits of premixed natural gas/oxygen/steam mixtures," Chem. jEng ournal, pp. 633-638, 2010.

[9] H.-J. P. J.-R.- Chen, H.-Y. Tsai, J.-H. Chien, Flow and flame visualization near the upper flammability limits of methane/air and propane/air mixtures at elevated pressures, 24th ed. J. Loss Prevent, 2011.

[10] K.-Y. C. H.-J. Liaw, A model for predicting temperature effect on flammability. 2016.

[11] H. O. Y. Koshiba, T. Nishida, N. Morita, "Explosion behaviour of n-alkane/nitrous oxide mixtures," P. Saf, Ed. Environ: Prot, 2015, pp. 11-15.

[12] D. A. C. C.V. Mashuga, "Flammability zone prediction using calculated adiabatic flame temperatures," Process Saf: Progress, 1999, pp. 127-134.

[13] H. O. Y. Koshiba, T. Nishida, N. Morita, "Explosion behaviour of n-alkane/nitrous oxide mixtures," in Process Saf. Environ, 2015, p. 11-15.

[14] G. Y. C.K. Law, D.L. Zhu, "Propagation and extinction of stretched premixed flames," 21st Symp. Combust., 1986.

[15] F. A. Williams, Combustion Theory, Benjamin/C. CA/Reading, 1985.

[16] H. S. M. K. Lakshmisha, P.J. Paul, "On the flammability limit and heat loss in flames with detailed chemistry," pp. 433-440, 1991.

[17] C.. F.N. Egolfopoulos, A.T. Holley, "An assessment of the lean flammability limits of CH4/air and C3H8/air mixtures at engine-like conditions," Combust, pp. 3015-3022, 2007.

[18] L. P. de G. F. Van den Schoor, R.T. Hermanns, J.A. van Oijen, F. Verplaetsen, "Comparison and evaluation of methods for the determination of flammability limits, applied to methane/hydrogen/air mixtures, J. Hazard," J. Hazard, pp. 573-581, 2008.

[19] J. B. F. Van den Schoor, F. Verplaetsen, "Calculation of the upper flammability limit of methane/air mixtures et elevated pressures and temperatures," no. 153, 2008.

[20] E. S. G. Pio, "The effect of ultra-low temperature on the flammability limits of a methane/air/diluent mixtures," J. Hazard, vol. 362, pp. 224-229.

[21] A. F. Sudarma and M. H. Morsy, "Numerical study of non-premixed air-methane swirl combustor flows using RANS method," IOP Conf. Ser. Mater. Sci. Eng., vol. 453, no. 1, 2018. 